\title{
Dietary choline supplementation attenuated high-fat diet-induced inflammation through regulation of lipid metabolism and suppression of NFKB activation in juvenile black seabream (Acanthopagrus schlegelii)
}

\author{
Min Jin ${ }^{1}+$ (D), Tingting $\operatorname{Pan}^{1} \dagger$, Douglas R. Tocher ${ }^{2}$, Mónica B. Betancor ${ }^{2}$, Óscar Monroig ${ }^{3}$, Yuedong Shen ${ }^{1}$, \\ Tingting Zhu ${ }^{1}$, Peng Sun ${ }^{1}$, Lefei Jiao ${ }^{1}$ and Qicun Zhou ${ }^{1}$ \\ ${ }^{1}$ Laboratory of Fish and Shellfish Nutrition, School of Marine Sciences, Ningbo University, Ningbo 315211, People's Republic of China \\ ${ }^{2}$ Faculty of Natural Sciences, Institute of Aquaculture, University of Stirling, Stirling FK9 4LA, UK \\ ${ }^{3}$ Instituto de Acuicultura Torre de la Sal, Consejo Superior de Investigaciones Cientificas (LATS-CSIC), 12595 Ribera de Cabanes, Castellón, Spain
}

(Received 3 September 2019 - Final revision received 10 October 2019 - Accepted 11 October 2019)

Journal of Nutritional Science (2019), vol. 8, e38, page 1 of 11

doi:10.1017/jns.2019.34

Abstract

The present study aimed to investigate whether dietary choline can regulate lipid metabolism and suppress NFkB activation and, consequently, attenuate inflammation induced by a high-fat diet in black sea bream (Acanthopagrus schlegelii). An 8-week feeding trial was conducted on fish with an initial weight of $8 \cdot 16 \pm 0.01$ g. Five diets were formulated: control, low-fat diet (11\%); HFD, high-fat diet (17\%); and HFD supplemented with graded levels of choline (3, 6 or $12 \mathrm{~g} / \mathrm{kg}$ ) termed HFD + C1, HFD + C2 and HFD + C3, respectively. Dietary choline decreased lipid content in whole body and tissues. Highest TAG and cholesterol concentrations in serum and liver were recorded in fish fed the HFD. Similarly, compared with fish fed the HFD, dietary choline reduced vacuolar fat drops and ameliorated HFD-induced pathological changes in liver. Expression of genes of lipolysis pathways were up-regulated, and genes of lipogenesis down-regulated, by dietary choline compared with fish fed the HFD. Expression of $n f \kappa b$ and pro-inflammatory cytokines in liver and intestine was suppressed by choline supplementation, whereas expression of anti-inflammatory cytokines was promoted in fish fed choline-supplemented diets. In fish that received lipopolysaccharide to stimulate inflammatory responses, the expression of $n f k b$ and pro-inflammatory cytokines in liver, intestine and kidney were all down-regulated by dietary choline compared with the HFD. Overall, the present study indicated that dietary choline had a lipid-lowering effect, which could protect the liver by regulating intrahepatic lipid metabolism, reducing lipid droplet accumulation and suppressing NFKB activation, consequently attenuating HFD-induced inflammation in $A$. schlegelii.

Key words: Choline: High-fat diets: Lipid metabolism: Inflammation: NFKB

Lipids are important energy-dense macronutrients that are efficiently utilised by most fish species and, consequently, there is a tendency to use high-fat diets (HFD) in intensive aquaculture due to the protein-sparing and growth-promoting effects of dietary lipid ${ }^{(1,2)}$. However, HFD commonly cause excess fat accumulation in liver or visceral fat tissue in farmed fish, leading to liver injury and lipid metabolism disorders ${ }^{(3-8)}$. Similar results have been reported in mammals, indicating that excess dietary fat can cause injury in the liver and various other tissues and organs ${ }^{(9-13)}$. HFD-induced obesity in rodents has shown conclusively that hepatic steatosis is associated with a state of chronic hepatic inflammation ${ }^{(14)}$. Recently, studies

Abbreviations: acc $\alpha$, acetyl-CoA carboxylase $\alpha$; ALT, alanine aminotransferase; AST, aspartate aminotransferase; $c$ t1 $a$, carnitine palmitoyltransferase $1 \mathrm{a} ;$ fas, fatty acid synthase; HFD, high-fat diet; HFD + C1, HFD + choline (3 g/kg); HFD + C2, HFD + choline (6 g/kg); HFD + C3, HFD + choline (12 g/kg); hsl, hormone-sensitive lipase; LPS, lipopolysaccharide; qPCR, quantitative PCR; srebp-1, sterol regulatory element-binding protein-1; tg $\beta-1$, transforming growth factor $\beta-1$.

* Corresponding authors: Professor Qi-Cun Zhou, fax +86 574876 09878, email zhouqicun@nbu.edu.cn; Dr Min Jin, fax +86 57487609878 , email jinmin@nbu.edu.cn †These authors contributed equally to this work and should be considered co-first authors. 
demonstrated that HFD could impair lipid homoeostasis and induce inflammatory responses in several marine fish species, including black seabream (Acanthopagrus schlegelii), blunt snout bream (Megalobrama amblycephala) and large yellow croaker

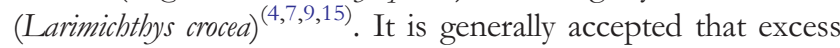
fat deposition is associated with altered tissue lipid metabolism, including lipogenesis and lipolysis. Previous studies demonstrated that fat deposition could be decreased by downregulating the expression of lipogenesis pathway genes such as sterol regulatory element-binding protein-1(srebp-1), acetylCoA carboxylase $\alpha(a c c \alpha)$ and fatty acid synthase (fas), and/ or up-regulation of lipolysis pathway genes such as PPAR $\alpha$ (ppar $\alpha)$, hormone-sensitive lipase ( $b s l)$ and carnitine palmitoyltransferase 1A $\left(c_{p} t 1 a\right)^{(16-19)}$. In addition, adiponectin, a hormone involved in the regulation of glucose metabolism and fatty acid breakdown in mammals, could lower intracellular lipid content ${ }^{(20)}$. Therefore, dietary supplements that can regulate lipid metabolism or adiponectin and, consequently, reduce excess lipid deposition, alleviate hepatic steatosis and attenuate inflammation response would be highly beneficial.

Choline has been shown to be an essential vitamin for fish, playing a vital role in maintaining cell structure and lipid transport in and out of the cells ${ }^{(21,22)}$. It is well known that choline is a key component of both phosphatidylcholine and acetylcholine, a neurotransmitter ${ }^{(23)}$. Recent studies reported that dietary choline supplementation affected hepatic transport and lipid deposition in various fish species, which suggested that dietary choline could reduce hepatic lipid content and influence expression of lipid metabolism genes ${ }^{(23-26)}$. Moreover, previous studies demonstrated that dietary choline could modulate immune responses by reducing expression of pro-inflammatory biomarkers such as TNF- $\alpha$ (tnf $\alpha$ ), IL-1 $\beta$ (il-1 $\beta)$ and NFKB $(n f \kappa b)$, and up-regulating mRNA expression of anti-inflammatory cytokine IL-10 (il-10) and transforming growth factor $\beta-1(\operatorname{tg} \beta-1)$ in vertebrates including fish ${ }^{(27-29)}$. However, there are few studies investigating the possible mechanisms whereby dietary choline affects lipid metabolism and subsequently reduces inflammatory response.

Lipopolysaccharide (LPS) is a structural component of the outer membrane of Gram-negative bacteria and one of the most effective stimulators of the immune system, and has been widely used as an experimental model for bacterial infection in animals ${ }^{(4,28,30-33)}$. Furthermore, the LPS inflammation model has been commonly used to evaluate acute-phase responses and the release of pro-inflammatory cytokines through the activation of $n f \kappa b^{(4,34)}$. NFKB is a transcription factor belonging to the 'Rel' family that represents a crucial intracellular signal transduction system involved in several inflammatory responses, through interaction with the inhibitory $\kappa \mathrm{B}(\mathrm{I} \kappa \mathrm{B})$ proteins ${ }^{(35)}$. Activation of $\mathrm{NF \kappa B}$ promotes the expression of inflammatory molecules, such as IL-6, IL-8 and TNF $\alpha^{(36)}$. Hence, NFKB is a key nuclear transcription factor tightly linked to the inflammatory response.

Black seabream (A. scblegelii) is a very popular and commercially important marine fish species cultured in China, Japan, Korea and other countries in Southeast Asia, and has been regarded as an excellent aquaculture species for intensive culture since it exhibits rapid growth, high disease resistance, and can tolerate a wide range of environmental conditions ${ }^{(7)}$. Besides, black seabream is a validated experimental model for HFD-induced inflammation as confirmed previously ${ }^{(7)}$. The production of high-quality fish for human consumption requires healthy fish and, therefore, improving fish health is a priority in aquaculture. In the present study, we aimed to investigate how HFD can affect lipid metabolism and cause inflammation by exploring the impacts of dietary choline, supplemented to HFD, as a mechanism to attenuate HFDinduced inflammatory responses.

\section{Materials and methods}

\section{Ethics statement}

Animal experimentation within the present study was conducted in accordance with the Animal Research Institute Committee guidelines of Ningbo University, China and approved by the Committee of the Animal Research Institute, Ningbo University, China.

\section{Experimental design and diet preparation}

Five isonitrogenous (about $42 \%$ crude protein) experimental diets with two levels of lipid (about $11 \%$ and about $17 \%$ crude lipid) were formulated with the diets containing the higher lipid level supplemented with graded levels of choline (Sinopharm Chemical Reagent Co., Ltd). The diets were termed: control, low-fat diet; HFD, high-fat diet; HFD + C1, HFD plus choline $(3 \mathrm{~g} / \mathrm{kg}$ dry diet); HFD $+\mathrm{C} 2$, HFD plus choline ( $6 \mathrm{~g} / \mathrm{kg}$ dry diet); HFD + C3, HFD plus choline (12 $\mathrm{g} / \mathrm{kg}$ dry diet) (Table 1). Fishmeal, soyabean protein concentrate, soyabean meal and wheat flour were used as protein sources, with fish oil, palmitic acid and soyabean lecithin

Table 1. Formulation and composition of the experimental diets (\% DM)

\begin{tabular}{|c|c|c|c|c|c|}
\hline & \multicolumn{5}{|c|}{ Diets } \\
\hline & Control & HFD & $\mathrm{HFD}+\mathrm{C} 1$ & $\mathrm{HFD}+\mathrm{C} 2$ & $\mathrm{HFD}+\mathrm{C} 3$ \\
\hline \multicolumn{6}{|l|}{ Ingredients } \\
\hline Fish meal & 26.000 & 26.000 & $26 \cdot 000$ & $26 \cdot 000$ & $26 \cdot 000$ \\
\hline $\begin{array}{l}\text { Soyabean protein } \\
\text { concentrate }\end{array}$ & $10 \cdot 000$ & $10 \cdot 000$ & $10 \cdot 000$ & $10 \cdot 000$ & $10 \cdot 000$ \\
\hline Soyabean meal & $20 \cdot 000$ & $20 \cdot 000$ & $20 \cdot 000$ & $20 \cdot 000$ & $20 \cdot 000$ \\
\hline Wheat flour & $24 \cdot 300$ & $24 \cdot 300$ & $24 \cdot 300$ & $24 \cdot 300$ & $24 \cdot 300$ \\
\hline Fish oil & 8.000 & 8.000 & 8.000 & 8.000 & 8.000 \\
\hline Palmitic acid & 0.000 & 6.000 & 6.000 & 6.000 & 6.000 \\
\hline Soyabean lecithin & 1.000 & 1.000 & 1.000 & 1.000 & 1.000 \\
\hline Vitamin premix ${ }^{\star}$ & 0.500 & 0.500 & 0.500 & 0.500 & 0.500 \\
\hline Mineral premix ${ }^{*}$ & 2.000 & 2.000 & 2.000 & 2.000 & 2.000 \\
\hline Choline chloride & 0.000 & 0.000 & 0.300 & 0.600 & 1.200 \\
\hline $\mathrm{Ca}\left(\mathrm{H}_{2} \mathrm{PO}_{4}\right)_{2}$ & 1.000 & 1.000 & 1.000 & 1.000 & 1.000 \\
\hline Cellulose & $7 \cdot 200$ & 1.200 & 0.900 & 0.600 & 0.000 \\
\hline \multicolumn{6}{|c|}{ Proximate composition (\%) } \\
\hline DM & 90.04 & 89.43 & 89.78 & 89.72 & 89.59 \\
\hline Crude protein & $40 \cdot 48$ & $40 \cdot 79$ & 41.49 & 41.68 & 41.92 \\
\hline Crude lipid & $10 \cdot 82$ & $16 \cdot 75$ & $16 \cdot 42$ & $16 \cdot 37$ & $16 \cdot 39$ \\
\hline Ash & $9 \cdot 30$ & 9.45 & 9.44 & 9.41 & 9.40 \\
\hline
\end{tabular}

HFD, high-fat diet; HFD + C1, HFD + choline (3 g/kg); HFD + C2, HFD + choline (6 g/kg); $\mathrm{HFD}+\mathrm{C} 3, \mathrm{HFD}+$ choline $(12 \mathrm{~g} / \mathrm{kg})$.

* The vitamin premix and mineral mixture were purchased from Ningbo Tech-Bank Feed Co. Ltd. 
used as the main lipid sources. All ingredients were purchased from Ningbo Tech-Bank Feed Co. Ltd. The experimental diets were produced according to the method described in detail previously ${ }^{(7)}$. Briefly, the ground ingredients were mixed in a Hobart type mixer and cold-extruded pellets produced (F-26; Machine Factory of South China University of Technology) with pellet strands cut into uniform sizes (2 and $4 \mathrm{~mm}$ diameter pellets) (G-250; Machine Factory of South China University of Technology). Pellets were steamed for $30 \mathrm{~min}$ at $90^{\circ} \mathrm{C}$, and then air-dried to approximately 10 $\%$ moisture, sealed in vacuum-packed bags and stored at $-20^{\circ} \mathrm{C}$ until used in the feeding trial.

\section{Feeding trial and experimental conditions}

Juvenile black seabream (initial weight $8 \cdot 16 \pm 0.01 \mathrm{~g}$ ) were obtained from a local commercial hatchery at Xiangshan Bay, Ningbo, China. Prior to the experiment, the black seabream juveniles were acclimatised for 2 weeks and fed with a commercial diet $(45 \%$ dietary protein, $12 \%$ crude lipid; Ningbo Tech-Bank Corp.). A completely randomised trial design was implemented. Briefly, a total of 450 black seabream juveniles were randomly allocated to fifteen floating net cages $(1.5 \mathrm{~m} \times 1.5 \mathrm{~m} \times 2.0 \mathrm{~m})$ corresponding to triplicate cages of the five dietary treatments. Fish were hand-fed to apparent satiation twice daily at 07.00 and 17.00 hours over 8 weeks. During the experimental period, physico-chemical conditions including temperature $\left(26 \cdot 6-30 \cdot 7^{\circ} \mathrm{C}\right)$, salinity $(25.53-27.86$ $\% 0$, dissolved $\mathrm{O}_{2}(4 \cdot 7-6 \cdot 8 \mathrm{mg} / \mathrm{l})$ and $\mathrm{pH}(8 \cdot 0-8 \cdot 1 \mathrm{mg} / \mathrm{l})$ were monitored daily (YSI Proplus; YSI).

\section{Sample collection}

At the end of the feeding trial, fish were sampled $24 \mathrm{~h}$ after the last feed, with all fish (other than six fish used for the LPS challenge test) anaesthetised with tricaine methane sulfonate (MS-222). All fish in each cage were weighed and counted to determine weight gain, specific growth rate, feed efficiency and survival. Five fish from each cage (fifteen per treatment) were pooled (n 3) and used for proximate composition of the whole body. Liver samples were collected and pooled from a further three fish per cage $(n)$ and stored at $-80^{\circ} \mathrm{C}$ prior to analysis of adiponectin, TAG and cholesterol content. Liver and intestine samples were also rapidly collected from five fish in each cage and stored at $-80^{\circ} \mathrm{C}$ prior to analysis of gene expression (pools of five fish per cage, $n$ 3). The liver was collected from one fish per cage into $4 \%$ paraformaldehyde for histological analysis. Blood samples were taken from the caudal vein of eight fish per cage using $1.5 \mathrm{ml}$ syringes.

\section{Proximate composition analysis}

Crude protein, crude lipid, moisture and ash contents of diets as well as the lipid content of whole fish, muscle and liver were determined according to the methods of the Association of Official Analytical Chemists ${ }^{(37)}$. Briefly, crude protein content was determined via the Dumas combustion method with a protein analyser (FP-528; Leco). Moisture was determined by drying the samples to a constant weight at $105^{\circ} \mathrm{C}$. Crude lipid contents were determined by Soxhlet extraction using diethyl ether (Soxtec System HT6; Tecator). Ash contents were determined using a muffle furnace at $550^{\circ} \mathrm{C}$ for $8 \mathrm{~h}$.

\section{Assay of serum and hepatic biochemical indices}

Blood was assayed within $24 \mathrm{~h}$ of collection after storage at $4^{\circ} \mathrm{C}$, with serum collected by centrifugation at $956 \mathrm{~g}$ for $10 \mathrm{~min}$ at $4^{\circ} \mathrm{C}$. Serum biochemical indices including total protein, albumin, TAG, cholesterol, glucose contents and the activities of alkaline phosphatase, aspartate aminotransferase (AST) and alanine aminotransferase (ALT) were measured by automatic biochemical analyser (Selectra Pro-M 13-7476) according to the manufacturer's instructions (Nanjing Jiancheng Bioengineering Institute).

Liver samples were homogenised in nine volumes (w/v) of ice-cold physiological saline $(0.89 \%$; w/v), and then centrifuged as above. The contents of adiponectin (Shanghai Jiancheng Bioengineering Institute), TAG and cholesterol (Nanjing Qiaodu Biotechnology Co., Ltd) were assayed using commercial kits according to the manufacturer's instructions by Multiskan spectrum (Thermo).

\section{Histological analysis of liver}

Fresh liver tissue was fixed with $4 \%$ paraformaldehyde before paraffin sections were prepared (Servicebio). Briefly, after fixation for at least $24 \mathrm{~h}$, tissue samples were trimmed appropriately in a fume hood before being dehydrated in ethanol with concentration increasing incrementally from $75 \%$ to $100 \%$. Liver samples were then embedded in paraffin and sliced into sections of $4 \mu \mathrm{m}$ using a microtome. They were stained with haematoxylin and eosin and images were acquired under a microscope (Nikon Eclipse CI).

Total RNA extraction, reverse transcription and real-time PCR

Gene expression was determined by reverse-transcriptase quantitative PCR (qPCR) as follows. Total RNA was extracted from tissues (liver, intestine and kidney) of juvenile black seabream using Trizol reagent (Takara) according to the manufacturer's instructions. Quantity and quality of isolated RNA were determined spectrophotometrically (Nanodrop 2000; Thermo Fisher Scientific) and on a $1.2 \%$ denaturing agarose gel, respectively. The cDNA was prepared from $1000 \mathrm{ng}$ of DNAase-treated RNA and synthesised using a PrimeScript ${ }^{\mathrm{TM}}$ RT Reagent Kit with gDNA Eraser (Perfect Real Time; Takara). The housekeeping gene $\beta$-actin was used as the reference gene after confirming its stability across the experimental treatments. Specific primers for the candidate genes $n f \kappa b, i l-1 \beta, \operatorname{tnf\alpha }, \operatorname{tg} \beta \beta-1, i l-10, a c c \alpha, f a s, s r e b p-1, \mid p l, c p t 1 a$, hsl and ppana used for qPCR were designed by Primer Premier 5.0 (Table 2). Amplification was performed using a quantitative thermal cycler (Lightcycler 96; Roche). The qPCR assays were performed in a total volume of $20 \mu \mathrm{l}$, containing $1.0 \mu$ of each primer, $10 \mu$ l of $2 \times$ conc. SYBR Green I Master (Roche), $2 \mu \mathrm{l}$ of $1 / 5$ diluted cDNA and $6 \mu \mathrm{l}$ diethyl pyrocarbonate (DEPC)-water. The thermal-cycling conditions 
Table 2. Primers for real-time quantitative PCR for inflammation related genes and $\beta$-actin of black seabream (Acanthopagrus schlegelii)

\begin{tabular}{|c|c|c|c|c|}
\hline Gene & Nucleotide sequence $\left(5^{\prime}-3^{\prime}\right)$ & Size (bp) & GenBank reference or publication & Functions \\
\hline \multirow[t]{2}{*}{$i-1 \beta$} & Forward: CATCTGGAGGCGGTGAA & 231 & JQ973887 & Pro-inflammation cytokine \\
\hline & Reverse: CGGTTTTGGTGGGAGGA & & & \\
\hline \multirow[t]{2}{*}{$\operatorname{tnf} \alpha$} & Forward: GTCCTGCTGTTTGCTTGG & 154 & AY335443 & Pro-inflammation cytokine \\
\hline & Reverse: AATGGATGGCTGCCTTGG & & & \\
\hline \multirow[t]{2}{*}{$n f-\kappa b$} & Forward: AGCCCAAGGCACTCTAGACA & 154 & MK922543 & Nuclear transcription factor \\
\hline & Reverse: GTTCTGGGCAGCTGTAGAGG & & & \\
\hline \multirow[t]{2}{*}{$\operatorname{tgff} \beta-1$} & Forward: GGGTTTCCAACTTCGGC & 209 & Xue et al. ${ }^{(39)}$ & Anti-inflammation cytokine \\
\hline & Reverse: TTGTGTCCGTGGAGCGT & & & \\
\hline \multirow[t]{2}{*}{ il-10 } & Forward: TGTCAAACGGTTCCTTGCAG & 172 & MK922542 & Anti-inflammation cytokine \\
\hline & Reverse: GGCATCCTGGGCTTCTATCT & & & \\
\hline \multirow[t]{2}{*}{$\operatorname{acc} \alpha$} & Forward: AGTAGCCTGATTCGTTGGT & 154 & KX066238 & Lipogenesis pathway \\
\hline & Reverse: AGTAGCCTGATTCGTTGGT & & & \\
\hline \multirow[t]{2}{*}{ fas } & Forward: AAGAGCAGGGAGTGTTCGC & 213 & KX066240 & Lipogenesis pathway \\
\hline & Reverse: TGACGTGGTATTCAGCCGA & & & \\
\hline \multirow[t]{2}{*}{ srebp-1 } & Forward: TGGGGGTAGGAGTGAGTAG & 247 & KX066235 & Lipogenesis pathway \\
\hline & Reverse: GTGAAGGGTCAGTGTTGGA & & & \\
\hline \multirow[t]{2}{*}{ cptla } & Forward: TGCTCCTACACACTATTCCCA & 203 & KX078572 & Lipolysis pathway \\
\hline & Reverse: CATCTGCTGCTCTATCTCCCG & & & \\
\hline \multirow[t]{2}{*}{ hsl } & Forward: AGCAACTAAGCССТССССАТC & 179 & KX066236 & Lipolysis pathway \\
\hline & Reverse: TCTTCACCCAGTCCGACACAC & & & \\
\hline \multirow[t]{2}{*}{ ppara } & Forward: ACGACGCTTTCCTCTTCCC & 183 & KX066234 & Lipolysis pathway \\
\hline & Reverse: GCCTCCСCCTGGTTTATTC & & & \\
\hline \multirow[t]{2}{*}{$\beta$-actin } & Forward: ACCCAGATCATGTTCGAGACC & 212 & Jiao et al. ${ }^{(38)}$ & Housekeeping gene \\
\hline & Reverse: ATGAGGTAGTCTGTGAGGTCG & & & \\
\hline
\end{tabular}

$\operatorname{tgf} \beta-1$, Transforming growth factor $\beta-1$; acc $\alpha$, acetyl-CoA carboxylase $\alpha$; fas, fatty acid synthase; srebp-1, sterol regulatory element-binding protein-1; cpt1a, carnitine palmitoyltransferase $1 \mathrm{a} ; h s l$, hormone-sensitive lipase.

used for qPCR were as follows: $95^{\circ} \mathrm{C}$ for $2 \mathrm{~min}$, followed by forty-five cycles of $95^{\circ} \mathrm{C}$ for $10 \mathrm{~s}, 58^{\circ} \mathrm{C}$ for $10 \mathrm{~s}$ and $72^{\circ} \mathrm{C}$ for $20 \mathrm{~s}$. Standard curves were generated using six different dilutions (in triplicate) of the cDNA samples, and the amplification efficiency was analysed using the equation $E=10^{(-1 / \text { slope })}-1^{(40)}$. The amplification efficiencies of all genes were approximately equal and ranged from 87 to $109 \%$. All gene expression data were presented relative to the expression of the control group (reference group). The expression levels of the target genes were calculated using the 2 method as described by Livak \& Schmittgen ${ }^{(41)}$.

\section{Lipopolysaccharide injection and sampling}

After the 8-week feeding trial, six fish in each cage were randomly collected for LPS challenge to intensify inflammatory responses. LPS (Escherichia coli 055:B5; Sigma-Aldrich) was dissolved in sterile PBS ( $\mathrm{pH}=7 \cdot 4)$ to a final concentration of $0 \cdot 5$ $\mathrm{mg} / \mathrm{ml}$. Fish from the HFD, HFD + C1, HFD + C2 and $\mathrm{HFD}+\mathrm{C} 3$ treatments were individually injected intraperitoneally with $0.2 \mathrm{ml}$ LPS at a dose of $2.5 \mathrm{mg} / \mathrm{kg}$ body weight. As control, fish were injected individually with the same volume of sterile PBS. Liver, intestine and kidney were collected from all fish $24 \mathrm{~h}$ after injection (samples were pooled per cage; $n 3$ per dietary treatment), and snap-frozen in liquid $\mathrm{N}_{2}$ and stored at $-80^{\circ} \mathrm{C}$ for later gene expression analysis of $n f \kappa b, i l-1 \beta, \operatorname{tnf} \alpha, \operatorname{tg} \beta-1$ and $i l-10^{(4,31,42,43)}$.

\section{Statistical analysis}

Results are presented as means with their standard errors (number of replicates as indicated). The relative gene expression results (qPCR analyses) were expressed as mean normalised ratios corresponding to the ratio between the copy number of the target gene and the copy number of the reference gene, $\beta$-actin. The homogeneity of variances (Levene's test) were checked prior to ANOVA followed by Tukey's honestly significant difference test at a significance level of $P \leq 0.05$ (IBM SPSS Statistics 20).

\section{Results}

\section{Growth performance, feed utilisation, survival and lipid} content

In the present study, no statistical differences were found in final body weight, weight gain, specific growth rate, feed efficiency or survival among the five groups $(P>0.05)$ (Table 3$)$. However, fish fed with the HFD had significantly higher lipid content in whole body and muscle compared with the control group $(P<0 \cdot 05)$. Furthermore, compared with the HFD treatment, the lipid content in muscle was significantly reduced by dietary choline supplementation $(P<0.05)$, and significantly lower lipid content in whole body was recorded in fish fed $\mathrm{HFD}+\mathrm{C}$, but liver lipid content was not significantly affected $(P>0 \cdot 05)$ (Fig. 1).

\section{Serum and hepatic biochemical indices}

In serum, the activities of AST and ALT were significantly higher in fish fed the HFD than in fish fed the other diets $(P<0.05)$, and dietary choline supplementation significantly decreased AST and ALT activities in fish fed the HFD $(P<$ 0.05) (Fig. 2(A)). In contrast, no significant differences were found in serum TAG and cholesterol contents among all 
Table 3. Growth response, feed utilisation and survival of juvenile black seabream (Acanthopagrus schlegelii) fed the experimental diets for 8 weeks (Mean values with their standard errors; $n 3$ )

\begin{tabular}{|c|c|c|c|c|c|c|c|c|c|c|c|}
\hline \multirow[b]{3}{*}{ Parameter } & \multicolumn{11}{|c|}{ Diets } \\
\hline & \multicolumn{2}{|c|}{ Control } & \multicolumn{2}{|c|}{ HFD } & \multicolumn{2}{|c|}{$\mathrm{HFD}+\mathrm{C} 1$} & \multicolumn{2}{|c|}{$\mathrm{HFD}+\mathrm{C} 2$} & \multicolumn{2}{|c|}{$\mathrm{HFD}+\mathrm{C} 3$} & \multirow[b]{2}{*}{ ANOVA $P$} \\
\hline & Mean & SEM & Mean & SEM & Mean & SEM & Mean & SEM & Mean & SEM & \\
\hline IBW (g) & 8.14 & 0.01 & $8 \cdot 16$ & 0.01 & $8 \cdot 16$ & 0.01 & $8 \cdot 16$ & 0.01 & $8 \cdot 16$ & 0.01 & 0.933 \\
\hline FBW (g) & 41.78 & 1.64 & 40.57 & 0.80 & $40 \cdot 23$ & 1.50 & 38.83 & 0.24 & 38.77 & 1.54 & 0.451 \\
\hline WG (\%)* & 412.91 & 19.50 & 397.39 & $9 \cdot 22$ & 393.25 & 17.69 & $376 \cdot 14$ & $2 \cdot 61$ & $375 \cdot 34$ & $18 \cdot 37$ & 0.406 \\
\hline SGR $(\% / d) \dagger$ & 2.92 & 0.07 & $2 \cdot 86$ & 0.03 & $2 \cdot 85$ & 0.07 & 2.79 & 0.01 & $2 \cdot 78$ & 0.07 & 0.410 \\
\hline FE (g/g)‡ & 0.60 & 0.03 & 0.57 & 0.01 & 0.56 & 0.03 & 0.54 & 0.00 & 0.54 & 0.03 & 0.330 \\
\hline Survival (\%)§ & 95.56 & 1.11 & 98.89 & 1.11 & 96.67 & 1.92 & 95.56 & 2.94 & 95.56 & $2 \cdot 22$ & 0.716 \\
\hline
\end{tabular}

HFD, high-fat diet; HFD + C1, HFD + choline (3 g/kg); HFD + C2, HFD + choline (6 g/kg); HFD + C3, HFD + choline (12 g/kg); IBW, initial body weight; FBW, final body weight; WG, weight gain; SGR, specific growth ratio; FE, feed efficiency.

* WG $(\%)=100 \times(($ final body weight - initial body weight $) /$ initial body weight $)$.

† SGR $(\% / \mathrm{d})=100 \times((\mathrm{Ln}$ final body weight $(\mathrm{g})-\mathrm{Ln}$ initial body weight $)(\mathrm{g}) / \mathrm{d})$

‡ $\mathrm{FE}=$ weight gain ( $\mathrm{g}$, wet weight)/feed consumed ( $\mathrm{g}$, dry weight).

$\S$ Survival $(\%)=100 \times$ (final fish number/initial fish number).

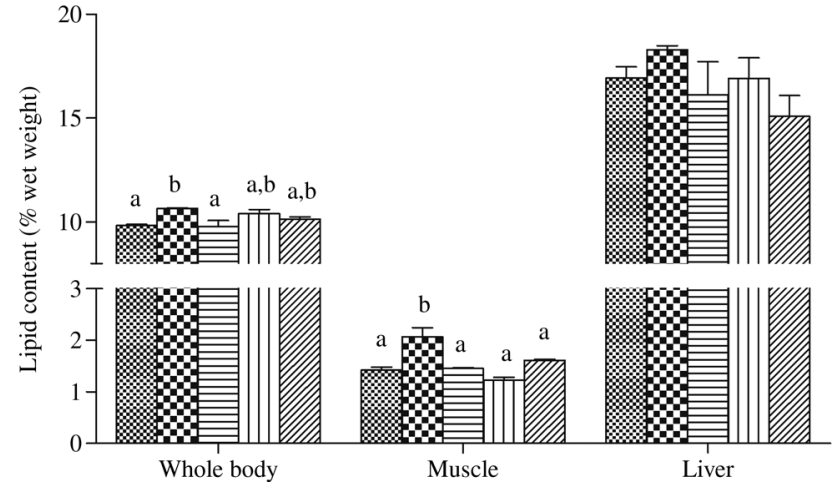

Fig. 1. Whole body, muscle and liver lipid content of the juvenile black seabream (Acanthopagrus schlegelii) (\% wet weight) fed the experimental diets

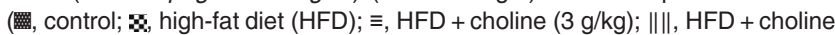
$(6 \mathrm{~g} / \mathrm{kg}) ; / / /, \mathrm{HFD}+$ choline $(12 \mathrm{~g} / \mathrm{kg}))$ for 8 weeks. Values are means $(n 3)$, with their standard errors represented by vertical bars. ${ }^{\mathrm{a}, \mathrm{b}}$ Mean values with unlike letters within each tissue were significantly different $(P<0.05)$.

treatments $(P>0 \cdot 05)$ (Fig. 2(B)). In liver, the cholesterol concentration was significantly higher in fish fed the HFD than in the control group, but was reduced in fish fed diets HFD + $\mathrm{C} 1, \mathrm{HFD}+\mathrm{C} 2$ and HFD $+\mathrm{C} 3(P<0 \cdot 05)$. Contrasting results were found for hepatic adiponectin, with significantly lower concentration recorded in fish fed the HFD compared with the control group $(P<0.05)$, and there was a clear trend for dietary choline to increase adiponectin compared with the HFD group, although no statistical differences were found $(P>0 \cdot 05)$ (Fig. 3).

\section{Hepatic histological analysis}

In fish fed the control diet, hepatocyte shape and structure were regular and normal, the nucleus with nucleolus was spherical, and basically in the middle of cells (Fig. 4(A)). In fish fed the HFD, hepatocyte nucleoli were vacuolar and had mostly disappeared, the nucleus and other organelles had lysed and liquefied to form large cysts, and cells contained many large vacuolar fat drops (Fig. 4(B)). In fish fed HFD + $\mathrm{C} 1, \mathrm{HFD}+\mathrm{C} 2$ and HFD $+\mathrm{C} 3$, the shapes of some cells were regular and parts of the cell structure remained normal, some of the nuclei with nucleoli were spherical, and vacuolar fat drops fewer and smaller compared with the HFD group, suggesting that dietary choline prevented or reduced the cell damage caused by the HFD (Fig. 4(C)-(E)).

\section{Lipogenesis and lipolysis pathway key markers}

The hepatic expression of cpt1 a was significantly up-regulated in fish fed the diets supplemented with choline supplementation compared with fish fed the $\operatorname{HFD}(P<0 \cdot 05)$. Similarly, hsl
(A)

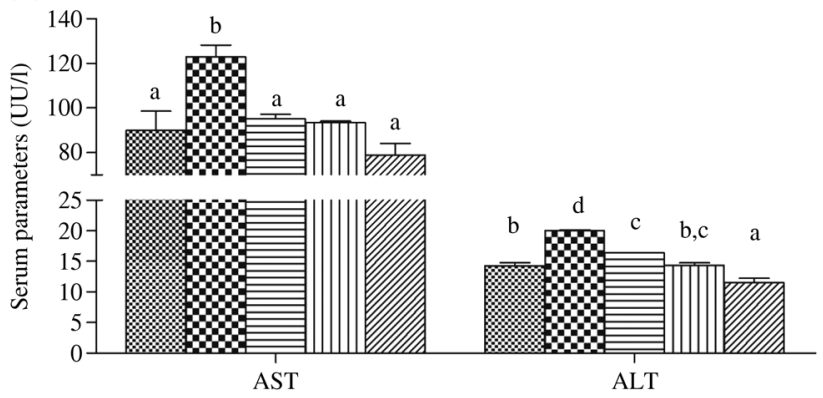

(B)

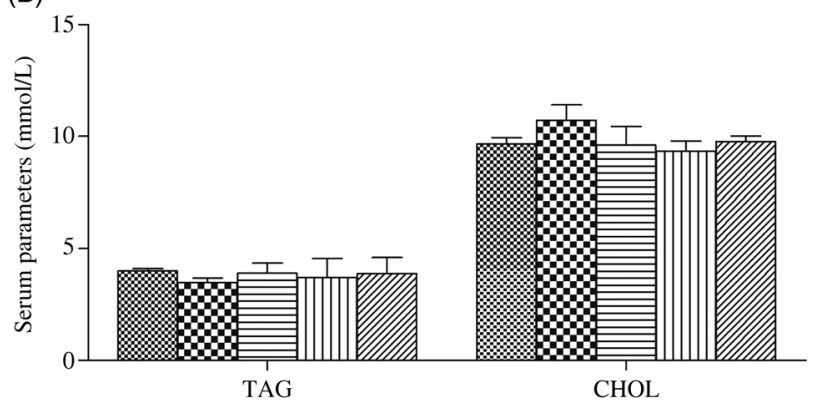

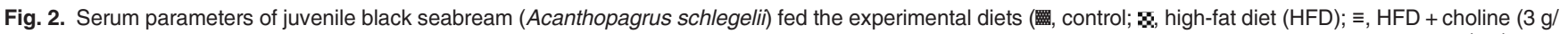
$\mathrm{kg})$; III, HFD + choline $(6 \mathrm{~g} / \mathrm{kg})$; ///, HFD + choline $(12 \mathrm{~g} / \mathrm{kg})$ ) for 8 weeks. Values are means $(n 3)$, with their standard errors represented by vertical bars. ${ }^{\text {a,b,c,d Mean }}$ values with unlike letters within each serum parameter were significantly different $(P<0.05)$. AST, aspartate aminotransferase; ALT, alanine aminotransferase; CHOL, cholesterol. 


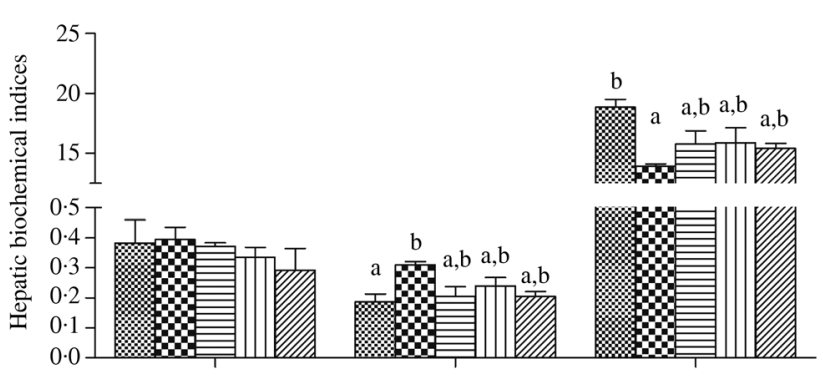

$\mathrm{TAG}(\mathrm{mmol} / \mathrm{g}$ protein) $\mathrm{CHOL}(\mathrm{mmol} / \mathrm{g}$ protein) $\mathrm{ADP}(\mathrm{ng} / \mathrm{mg}$ protein)

Fig. 3. Hepatic biochemical indices of juvenile black seabream

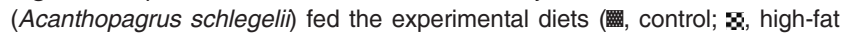
diet (HFD); 三, HFD + choline (3 g/kg); \|II, HFD + choline (6 g/kg); I/I, HFD + choline $(12 \mathrm{~g} / \mathrm{kg})$ ) for 8 weeks. Values are means $(n 3)$, with their standard errors represented by vertical bars. ${ }^{\mathrm{a}, \mathrm{b}}$ Mean values with unlike letters within each hepatic index were significantly different $(P<0.05)$. $\mathrm{CHOL}$, cholesterol; ADP, adiponectin.

expression was significantly up-regulated in fish fed HFD + C3 compared with the HFD group (Fig. 5(A)). On the contrary, the hepatic expression levels of srebp-1 and acco were significantly lower in fish fed the choline-supplemented diets compared with fish fed the HFD $(P<0 \cdot 05)$ (Fig. 5(B)).

\section{Inflammatory markers after 8-week feeding trial}

The expression levels of genes of the inflammatory response including nuclear transcription factor $n f \kappa b$, pro-inflammatory cytokines $i l-1 \beta$ and $\operatorname{tnf} \alpha$ as well as anti-inflammatory cytokine $\operatorname{tg} \beta \beta-1$ and $i l-10$ in liver and intestine are shown in Figs 6 and 7 , respectively. In liver and intestine, the expression levels of $n f \kappa b$ and $i l-1 \beta$ were significantly up-regulated in fish fed the HFD, and down-regulated in fish fed the diets supplemented with choline $(P<0 \cdot 05)$. In contrast, no significant differences were found in $\operatorname{tnf} \alpha$ mRNA expression $(P>0.05)$. The expression levels of $\operatorname{tg} \beta \beta-1$ and $i-10$ in liver and intestine were generally significantly up-regulated in fish fed the HFD with choline supplementation $(P<0 \cdot 05)$, other than hepatic to $\beta-1$ mRNA expression, which was not statistically different $(P>0 \cdot 05)$.

\section{Inflammatory markers after lipopolysaccharide injection}

The expression levels of genes of the inflammatory response including nuclear transcription factor $n f \kappa b$, pro-inflammatory cytokines $i l-1 \beta$ and $\operatorname{tnf} \alpha$ as well as anti-inflammatory cytokine $\operatorname{tg} \beta-1$ and $i l-10$ in liver, intestine and kidney of juvenile black seabream after LPS injection are presented in Figs 8-10, respectively. In all three tissues, the expression levels of $n f \kappa b$ were significantly higher in fish fed the HFD compared with fish fed the other diets, and down-regulated in fish fed the diets supplemented with choline $(P<0 \cdot 05)$. Similarly, the pro-inflammatory cytokines $i l-1 \beta$ and tnfo were decreased by dietary choline supplementation compared with fish fed the HFD $(P<0.05)$, although some differences were not statistically significant $(P>0 \cdot 05)$. In contrast, expression levels of the anti-inflammatory cytokine il-10 in liver and kidney were significantly lower in fish fed the HFD, and significantly up-regulated by choline supplementation $(P<0 \cdot 05)$. However, although there was a trend of increasing expression of $i-10$ in intestine in diets supplemented with choline, this was not significant $(P>0.05)$. Similar results were also
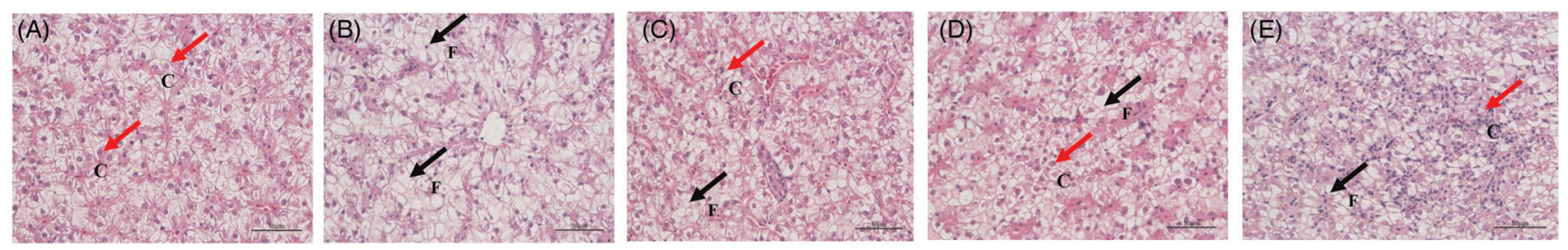

Fig. 4. Paraffin section of liver in juvenile black seabream (Acanthopagrus schlegeli). The liver section was stained with haematoxylin and eosin to enhance the contrast $(400 \times)$. (A) Paraffin section of liver in the control group; (B) paraffin section of liver in the high-fat diet (HFD) group; (C) paraffin section of liver in the HFD + choline (3 g/kg) group; (D) paraffin section of liver in the HFD + choline (6 g/kg) group; (E) paraffin section of liver in the HFD + choline (12 g/kg) group. C, cell nucleus; $F$, fat drop.

(A)

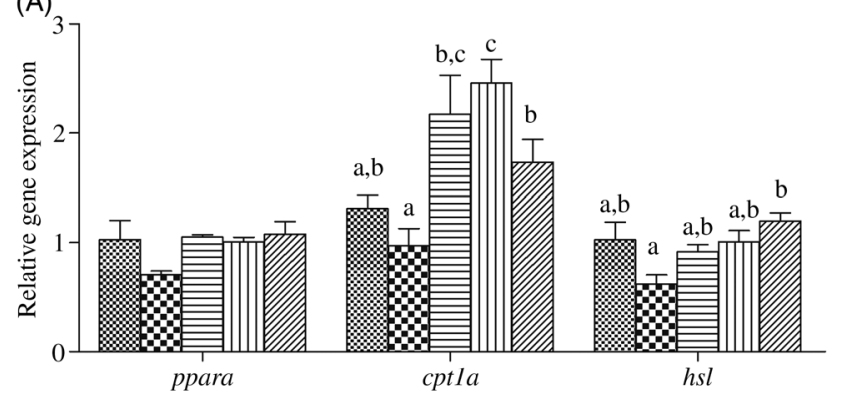

(B)

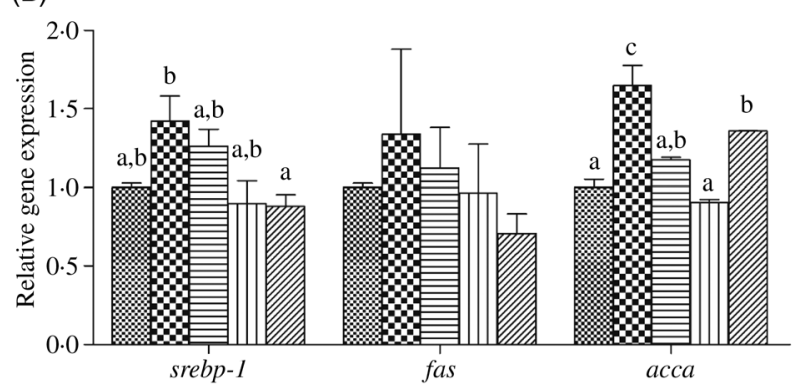

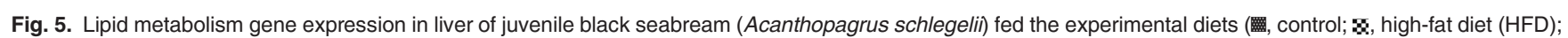
$\equiv$, HFD + choline (3 g/kg); III, HFD + choline (6 g/kg); /I/, HFD + choline (12 g/kg)) for 8 weeks. The control was used as the reference group, and the mRNA expression levels of target genes were normalised relative to the expression of $\beta$-actin. Values are means $(n 3)$, with standard errors represented by vertical bars. ${ }^{a, b, c}$ Mean values for each gene with unlike letters were significantly different $(P<0.05)$. cpt1a, Carnitine palmitoyltransferase 1a; $h s l$, hormone-sensitive lipase; srebp-1, sterol regulatory element-binding protein-1; fas, fatty acid synthase; acc $\alpha$, acetyl-CoA carboxylase $\alpha$. 


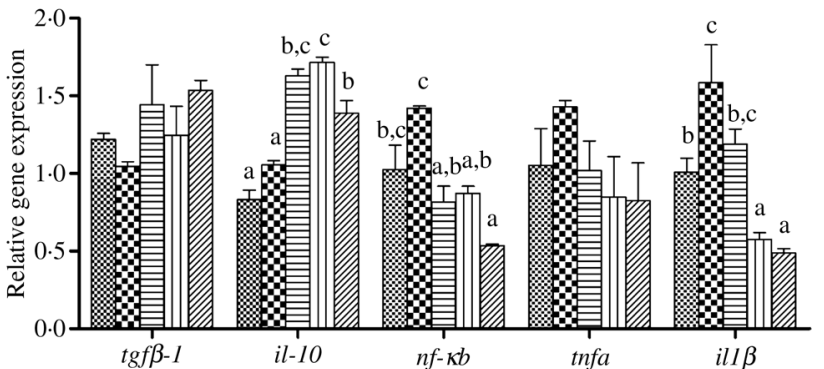

Fig. 6. Inflammation gene expression in liver of juvenile black seabream

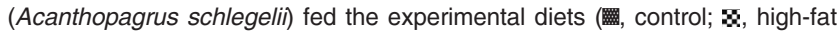
diet (HFD); 三, HFD + choline (3 g/kg); \|\|, HFD + choline (6 g/kg); ///, HFD + choline $(12 \mathrm{~g} / \mathrm{kg})$ ) for 8 weeks. The control was used as the reference group, and the mRNA expression levels of target genes were normalised relative to the expression of $\beta$-actin. Values are means $(n 3)$, with standard errors represented by vertical bars. ${ }^{a, b, c}$ Mean values for each gene with unlike letters were significantly different $(P<0.05)$. tgf $\beta-1$, Transforming growth factor $\beta-1$.

recorded for $\operatorname{tg} \beta-1$ expression in liver, intestine and kidney, with expressions tending to increase in fish fed the cholinesupplemented diets $(\mathrm{HFD}+\mathrm{C} 1, \mathrm{HFD}+\mathrm{C} 2$ and $\mathrm{HFD}+$ $\mathrm{C} 3)$, but not statistically significant $(P>0 \cdot 05)$.

\section{Discussion}

Previous studies have demonstrated that choline is a vitamin for young vertebrates, it is the most abundant vitamin constituent in most fish feeds, and it can provide active methyl groups, which can participate in the anabolism of important physiological compounds such as methionine, phospholipids

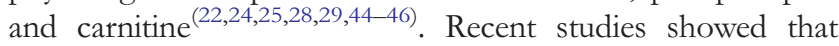
adequate dietary supplementation of choline could improve growth performance and feed utilisation in various fish species $^{(24,25,45-47)}$. In addition, weight gain increased significantly with increasing dietary choline supplementation when dietary lipid level was $11 \%$, and additional choline supplementation improved growth performance of $M$. amblycephala fed a HFD $(15 \% \text { lipid })^{(23,24)}$. However, in the present study, graded levels of dietary choline $(3,6$ or $12 \mathrm{~g} / \mathrm{kg}$ ) did not significantly affect the growth performance or feed utilisation of black seabream fed a HFD. The contrasting results could be explained by the

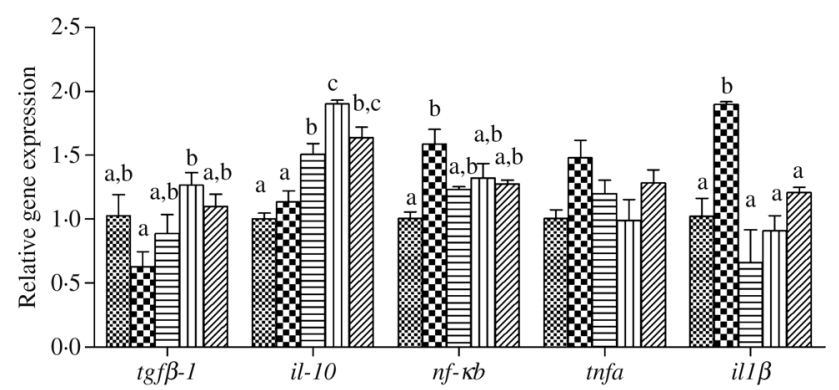

Fig. 7. Inflammation gene expression in intestine of juvenile black seabream (Acanthopagrus schlegelii) fed the experimental diets (爵, control; $\mathbf{z}$, high-fat diet (HFD); 三, HFD + choline (3 g/kg); \|l , HFD + choline $(6 \mathrm{~g} / \mathrm{kg})$; /I/, HFD + choline $(12 \mathrm{~g} / \mathrm{kg})$ ) for 8 weeks. The control was used as the reference group, and the mRNA expression levels of target genes were normalised relative to the expression of $\beta$-actin. Values are means ( $n 3)$, with standard errors represented by vertical bars. ${ }^{a, b, c}$ Mean values for each gene with unlike letters were significantly different $(P<0.05)$. tgf $\beta-1$, Transforming growth factor $\beta-1$.

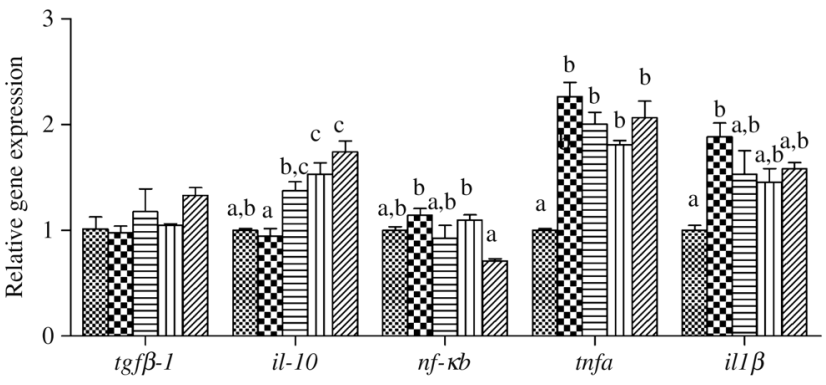

Fig. 8. Effects of lipopolysaccharide injection for $24 \mathrm{~h}$ on inflammation gene expression in liver of juvenile black seabream (Acanthopagrus schlegelii)

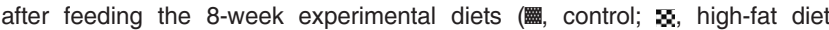
(HFD); झ, HFD + choline (3 g/kg); \|\| , HFD + choline (6 g/kg); //I, HFD + choline $(12 \mathrm{~g} / \mathrm{kg}))$. The control was used as the reference group, and the mRNA expression levels of target genes were normalised relative to the expression of $\beta$-actin. Values are means $(n 3)$, with standard errors represented by vertical bars. ${ }^{a, b, c}$ Mean values for each gene with unlike letters were significantly different $(P<0.05)$. tgf $\beta-1$, Transforming growth factor $\beta-1$.

higher dietary lipid level (16.5\%) used in the present study. Additionally, it might be related to the duration of the trial, which was only 8 weeks in the present study. The impact of a HFD on growth was shown previously to be time-dependent in $M$. amblycephala ${ }^{(4)}$. Furthermore, few studies have been conducted on the effects of dietary choline in fish fed HFD. However, although growth performance and feed utilisation in black seabream were not affected by HFD supplemented with choline, the present study revealed that dietary choline had impacts on lipid deposition, lipid metabolism and inflammation response that gave insights to possible regulatory mechanisms.

AST and ALT are two important aminotransferases in fish that are often used as general indicators of vertebrate liver function ${ }^{(23,48)}$. General cellular damage occurring in hepatic steatosis and injury in mammals is usually monitored by analysing leakage of cellular enzymes like AST and ALT into the blood $^{(49,50)}$, and similar mechanisms have also been confirmed in some fish species ${ }^{(23,51,52)}$. Significantly increased AST and ALT activities in serum were observed in fish fed diet HFD, consistent with a previous study in $M$. amblycephala fed

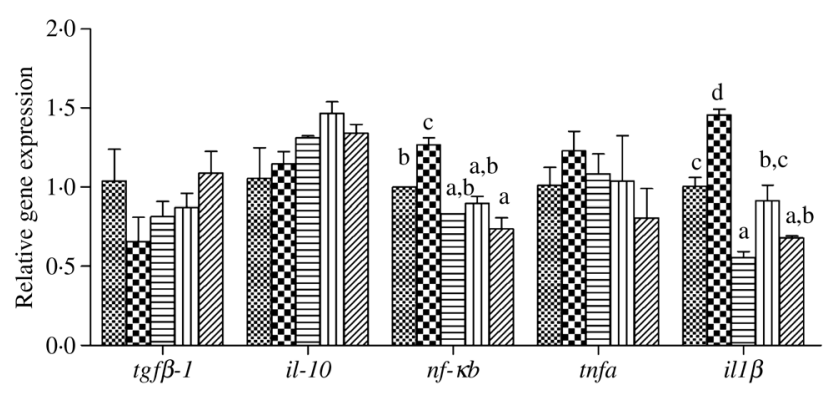

Fig. 9. Effects of lipopolysaccharide injection for $24 \mathrm{~h}$ on inflammation gene expression in intestine of juvenile black seabream (Acanthopagrus schlegelii)

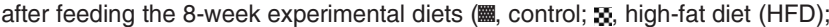
$\equiv$, HFD + choline (3 g/kg); ॥II, HFD + choline (6 g/kg); ///, HFD + choline (12 g/ $\mathrm{kg})$ ). The control was used as the reference group, and the mRNA expression levels of target genes were normalised relative to the expression of $\beta$-actin. Values are means ( $n 3)$, with standard errors represented by vertical bars. $\mathrm{a}, \mathrm{b}, \mathrm{c}, \mathrm{d}$ Mean values for each gene with unlike letters were significantly different $(P<0.05)$. tgf $\beta-1$, Transforming growth factor $\beta-1$. 


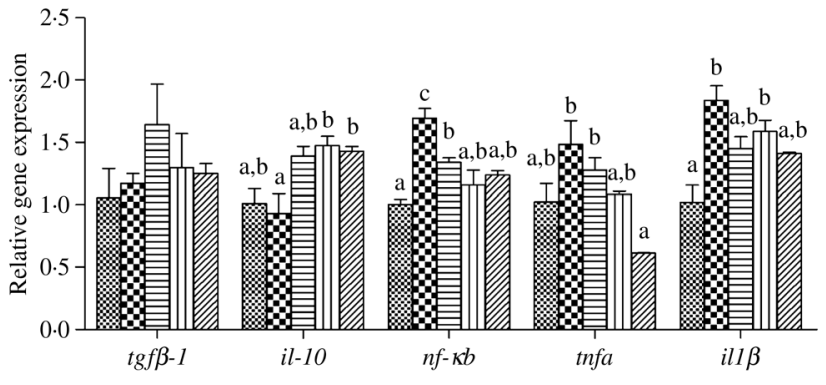

Fig. 10. Effects of lipopolysaccharide injection for $24 \mathrm{~h}$ on inflammation gene expression in kidney of juvenile black seabream (Acanthopagrus schlegelii)

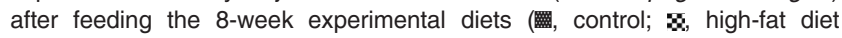
(HFD); 三, HFD + choline (3 g/kg); \|l\|, HFD + choline (6 g/kg); //I, HFD + choline $(12 \mathrm{~g} / \mathrm{kg}))$. The control was used as the reference group, and the mRNA expression levels of target genes were normalised relative to the expression of $\beta$-actin. Values are means ( $n 3)$, with standard errors represented by vertical bars. ${ }^{a, b, c}$ Mean values for each gene with unlike letters were significantly different $(P<0.05)$. tgf $\beta-1$, Transforming growth factor $\beta-1$.

$\mathrm{HFD}^{(23)}$. This suggested that there was a release of intracellular enzymes into the blood, indicating that possible damage to hepatocytes was induced by feeding HFD to black seabream. However, AST and ALT activities were reduced with increasing dietary choline in fish fed the HFD in the present study, demonstrating that dietary choline supplementation could mitigate the damage induced by a HFD in black seabream. Cholesterol and TAG levels in serum were unaffected by diet, whereas hepatic cholesterol and TAG concentrations were increased in fish fed the HFD, and decreased with choline supplementation, which was similar to results obtained in a previous study in Nile tilapia (Oreochromis niloticus) ${ }^{(6)}$. In addition, adiponectin plays a crucial role in hepatic lipid metabolism, with the beneficial effects of adiponectin in mammals being partially attributed to increased fatty acid oxidation in tissues such as liver and muscle ${ }^{(53)}$. In the present study, levels of adiponectin in liver were lowest in fish fed the HFD, and its level showed an increasing trend with dietary choline supplementation. This may indicate that choline supplementation to HFD treatments could reduce the risk of fat accumulation and hepatic steatosis in black seabream by reducing hepatic cholesterol and TAG, and restoring adiponectin concentration.

Choline has attracted attention as an important active substance in the body. Previous studies have confirmed that choline can act as an 'anti-fatty liver' factor by preventing or reducing lipid deposition in the liver. Subsequently, numerous studies on choline have been carried out to further explore the mechanism of choline's anti-fatty liver effect, and provide insight into its important role in nutrient metabolism and regulation ${ }^{(23-26,44,45)}$. In the present study, the highest lipid contents in whole body and muscle were recorded in fish fed the HFD compared with fish fed the other diets, and muscle lipid contents were reduced in fish fed the HFD treatments supplemented with choline. Similar results have been reported previously in various fish species, confirming that dietary choline could reduce lipid content of fish ${ }^{(23-26,45)}$. The mechanism of dietary choline supplementation on lipid deposition caused by the HFD was further studied by investigating histopathological changes. The results indicated the damage that feeding a HFD could cause in the liver of black seabream, with the nucleus and other organelles lysed, forming large cysts, and the presence of many large vacuolar fat drops in hepatocytes, similar to results reported previously in mice ${ }^{(54,55)}$. The present study indicated that dietary choline could prevent this damage to the liver and/or promote almost complete recovery. These findings confirmed results from other fish species that demonstrated inverse correlations between dietary choline levels and hepatic lipid contents ${ }^{(23,24,46)}$.

To further explore the lipid-lowering mechanism of dietary choline, we herein analysed the relative expression of some hepatic genes involved in lipolysis (ppar $\alpha, c p t 1 a$ and $b s L$ ) and lipogenesis (srepb-1, fas, and acco) pathways. It is believed that $\operatorname{PPAR} \alpha$ can promote fatty acid $\beta$-oxidation, and modulate expression of genes encoding several mitochondrial fatty acidcatabolising enzymes ${ }^{(56)}$, CPT1 is regarded as the main regulatory enzyme in fatty acid oxidation catalysing the conversion of cytosolic fatty acyl-CoA to fatty acyl-carnitine for entry into mitochondria $^{(57,58)}$, and HSL is an important enzyme involved in lipolysis ${ }^{(59)}$. The present study indicated that, in fish fed HFD supplemented with choline, cpt1a and hsl expression levels were up-regulated compared with fish fed the HFD. This demonstrated that dietary choline could promote lipolysis and fatty acid $\beta$-oxidation by up-regulating key genes in these pathways. Moreover, FAS can catalyse de novo fatty acid synthesis ${ }^{(60)}$, SREBP-1 is a major regulator of fatty acid and lipid biosynthesis ${ }^{(61)}$, and ACC $\alpha$ is a cytosolic enzyme that controls the production of malonyl-CoA and thus plays an important role in the biosynthesis of long-chain fatty acids ${ }^{(62-64)}$. In the present study, the expression levels of srebp-1 and acco showed a downward trend in the liver of fish fed the cholinesupplemented diets. These results were consistent with previous studies in $A$. schlegelii, Pseudosciaena crocea and $O$. niloticus $^{(6,7,15)}$. Hence, we conclude that dietary choline supplementation can reduce lipid deposition and alleviate hepatic steatosis through the regulation of lipid metabolism by up-regulating lipolysis and down-regulating lipogenesis pathway gene expression levels.

Previous studies revealed that HFD-induced lipid accumulation in the liver probably causes endoplasmic reticulum stress and accelerates the release of cytokines, thereby inducing inflammation ${ }^{(54,65-67)}$, which was confirmed in our previous study ${ }^{(7)}$. The nuclear transcription factor $n f \kappa b$ is a key upstream signalling molecule and when $\mathrm{NF}-\kappa \mathrm{B}$ is activated, it transfers into the nucleus and induces the expression of multiple inflammatory makers, including tnf- $\alpha$ and $i l-1 \beta^{(55,68)}$. In the present study, the transcript expression levels of nuclear transcription factor $n f \kappa b$ was up-regulated in fish fed the HFD both in the liver and intestine compared with fish fed the control diet. Consequently, the pro-inflammatory cytokines il-1 $\beta$ and tnf $\alpha$ were also up-regulated in fish fed the HFD without choline supplementation, confirming previous reports in $M$. amblycephala $^{(23)}$. The relative expression levels of $n f \kappa b$, il-1 $\beta$ and tnf $\alpha$ were all decreased in fish fed the diets with choline supplementation. These results were generally consistent with recent studies, indicating that moderate levels of dietary choline could alleviate inflammation by modulating NF- $\mathrm{B}$ signalling molecules $^{(26,28,29)}$. Moreover, $\operatorname{tg} \beta-1$ and $i l-10$ are two common antiinflammatory cytokines ${ }^{(28)}$ and they were up-regulated in the 

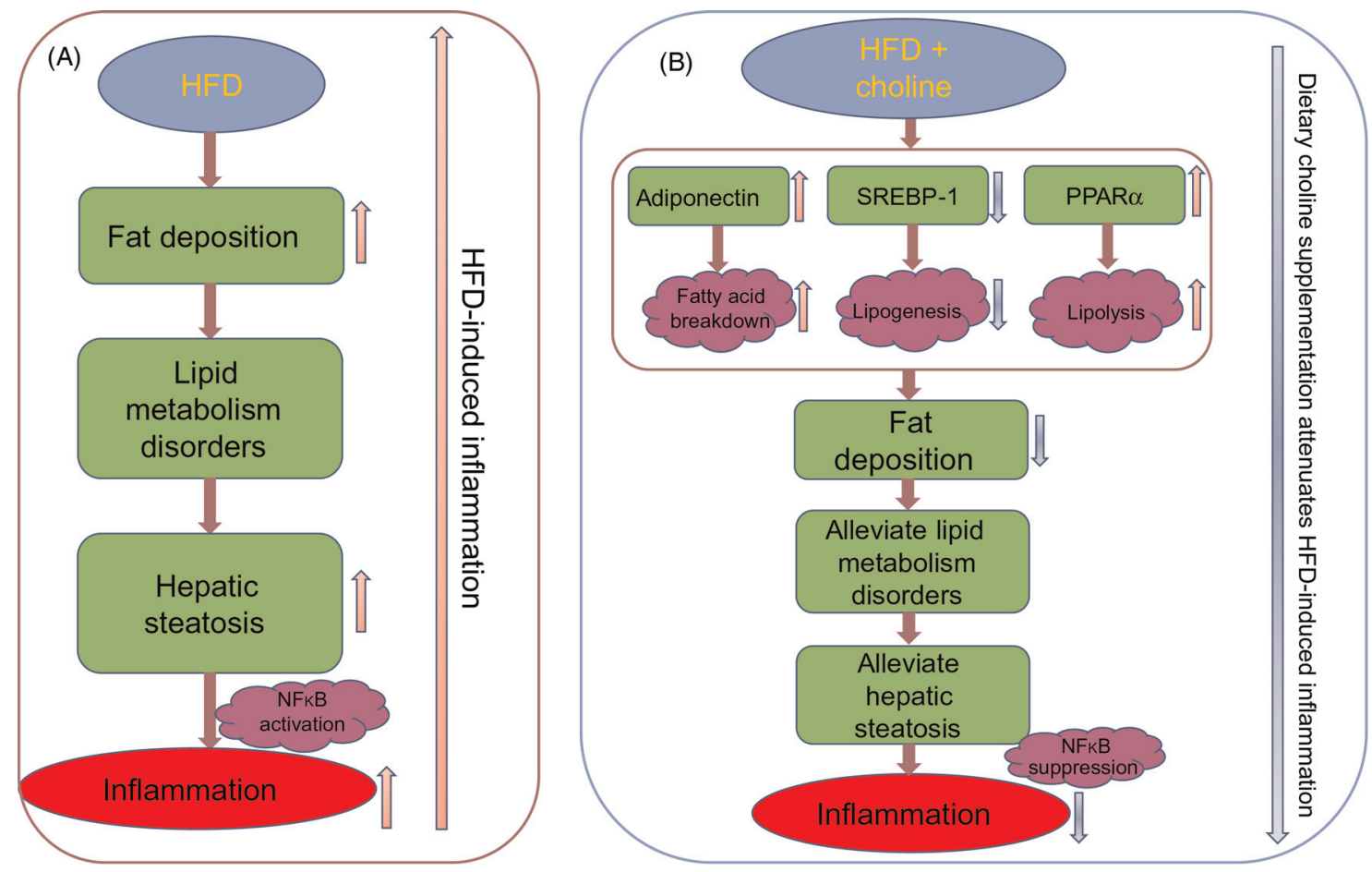

Fig. 11. Mechanism of high-fat diet (HFD)-induced inflammation of black seabream (Acanthopagrus schlegelii) (A); mechanism of dietary choline supplementation attenuation of HFD-induced inflammation response in black seabream (B). Pink arrows represent increase/up-regulate, blue arrows present decrease/down-regulate. SREBP-1, sterol regulatory element-binding protein-1.

liver and intestine by choline supplementation in the present study. Similar results were obtained in other fish species $^{(28,29)}$. Combined, these results indicated that dietary choline supplementation could reduce inflammatory responses. Hence, the present study demonstrated that fish fed the HFD caused lipid deposition, activated NFKB, and pro-inflammatory cytokines were released, thereby causing an inflammatory response. Dietary choline supplementation could attenuate inflammation by modulating NF- $\mathrm{KB}$ signalling molecules and increasing expression of antiinflammation markers.

In order to further verify that dietary choline supplementation has the effect of relieving inflammation, the LPS challenge experiment was conducted to promote a strong inflammation response. In teleosts, it is well known that inflammatory challenges in vivo and in vitro are able to induce the expression of genes of various pro-inflammatory factors with rapid kinetics ${ }^{(69)}$. Recently, it reported that the LPS effect varied depending upon the cytokine, stimulating (il-1 $\beta$ ), inhibiting $(\operatorname{tg} \beta \beta-1)$ or ineffective $(\operatorname{tnf}-\alpha)^{(43)}$. In the present study, the highest expression levels of $n f \kappa b, i l-1 \beta$ and $t n f \alpha$ in the liver, intestine and kidney were all recorded in fish fed the HFD $24 \mathrm{~h}$ after LPS injection, and all were lower in fish fed supplementary dietary choline. On the contrary, after LPS the lowest expression levels of $i l-10$ in the liver and kidney were found in fish fed the HFD, similar to results obtained in other fish species ${ }^{(4,28,30-32)}$. Likewise, il-10 expression levels were up-regulated by dietary choline supplementation. However, no significant differences were found in to $\beta-1$ expression in any tissue, although there was an upward trend. Therefore, the LPS injection experiment generally confirmed that dietary choline supplementation had an effect of relieving inflammation by regulating inflammatory cytokines expression.

\section{Conclusion}

In conclusion, the present study provided further insight to the mechanism of the HFD-induced inflammatory response that results in lipid accumulation, hepatic steatosis and NFKB activation (Fig. 11(A)). Furthermore, the present study revealed that dietary choline supplementation attenuated the HFD-induced inflammatory response (Fig. 11(B)). Dietary choline supplementation could increase hepatic adiponectin content and expression of lipolysis pathway genes, and reduce expression of lipogenesis pathway genes, promoting a lipid-lowering effect, and restoring lipid metabolism balance, and reducing hepatic steatosis and, subsequently, attenuating inflammation by modulating $\mathrm{NF}-\kappa \mathrm{B}$ signalling molecules to suppress pro-inflammatory genes and increasing expression of anti-inflammatory genes.

\section{Acknowledgements}

The authors are grateful to all the members in Fish and Shellfish Nutrition Laboratory of Ningbo University, without whose support we could not have finished this study.

This research was supported by the National Natural Science Foundation of China (grant no. 31802303), Natural Science Foundation of Ningbo (grant no. 2018A610343), National Key R \& D Program of China (2018YFD0900400), Key Research Program of Zhejiang Province of China (no. 2018C02037), Zhejiang Aquaculture Nutrition \& Feed Technology Service 
Team (ZJANFTST2017-2), the Open Fund of Zhejiang Provincial Top Key Discipline of Aquaculture in Ningbo University and K. C. Wong Magna Fund in Ningbo University.

M. J. and Q. C. Z. conceived and designed the experiments. T. T. P., Y. D. S., T. T. Z. and X. C. performed the experiments. T. T. P. and M. J. analysed the data. M. J. and T. T. P. contributed reagents/materials/analysis tools. T. T. P., M. J., Y. D. S., T. T. Z., X. C. and P. S. prepared the fish diets. T. T. P. conducted the fish feeding trial. T. T. P., M. J., Y. D. S., T. T. Z., X. C., P. S. and L. F. J. collected the samples. M. J., T. T. P., D. R. T., M. B. B. and Ó. M. wrote the paper. All authors contributed to and approved the manuscript.

The authors declare that there are no conflicts of interest.

\section{References}

1. Du ZY, Liu YJ, Tian LX, et al. (2015) Effect of dietary lipid level on growth, feed utilization and body composition by juvenile grass carp (Ctenopharyngodon idella). Aquac Nutr 11, 139-146.

2. Li X, Jiang Y, Liu W, et al. (2012) Protein-sparing effect of dietary lipid in practical diets for blunt snout bream (Megalobrama amblycephala) fingerlings: effects on digestive and metabolic responses. Fish Physiol Biochem 38, 529-541.

3. Cao XF, Dai YJ, Liu MY, et al. (2019) High-fat diet induces aberrant hepatic lipid secretion in blunt snout bream by activating endoplasmic reticulum stress-associated IRE1/XBP1 pathway. Biochim Biophys Acta 1864, 213-223.

4. Dai YJ, Jiang GZ, Yuan XY, et al. (2018) High-fat-diet-induced inflammation depresses the appetite of blunt snout bream (Megalobrama amblycephala) through the transcriptional regulation of leptin/mammalian target of rapamycin. Br J Nutr 120, 1422-1431.

5. Dai YJ, Cao XF, Zhang DD, et al. (2019) Chronic inflammation is a key to inducing liver injury in blunt snout bream (Megalobrama amblycephala) fed with high-fat diet. Dev Comp Immunol 97, 28-37.

6. He AY, Ning LJ, Chen LQ, et al. (2015) Systemic adaptation of lipid metabolism in response to low- and high-fat diet in Nile tilapia (Oreochromis niloticus). Physiol Rep 3, e12485.

7. Jin M, Pan T, Cheng X, et al. (2019) Effects of supplemental dietary L-carnitine and bile acids on growth performance, antioxidant and immune ability, histopathological changes and inflammatory response in juvenile black seabream (Acanthopagrus schlegelii) fed high-fat diet. Aquaculture 504, 199-209.

8. Nath S, Matozzo V, Bhandari D, et al. (2019) Growth and liver histology of Channa punctatus exposed to a common biofertilizer. Nat Prod Res 33, 1591-1598.

9. Aloui F, Charradi K, Hichami A, et al. (2016) Grape seed and skin extract reduces pancreas lipotoxicity, oxidative stress and inflammation in high fat diet fed rats. Biomed Pharmacother 84, 2020-2028.

10. Bonda TA, Szynaka B, Sokołowska M, et al. (2016) Interleukin 6 modulates PPAR $\alpha$ and PGC- $1 \alpha$ and is involved in high-fat diet induced cardiac lipotoxicity in mouse. Int J Cardiol 219, 1-8.

11. Chen F, Chen D, Zhao X, et al. (2017) Interleukin-6 deficiency facilitates myocardial dysfunction during high fat diet-induced obesity by promoting lipotoxicity and inflammation. Biocbim Biophys Acta $1863,3128$.

12. Jabri MA, Sakly M, Marzouki L, et al. (2017) Chamomile (Matricaria recutita L.) decoction extract inhibits intestinal glucose absorption and attenuates high fat diet-induced lipotoxicity and oxidative stress. Biomed Pharmacother 87, 153-159.

13. Mahmoudi M, Charradi K, Limam F, et al. (2018) Grape seed and skin extract as an adjunct to xenical therapy reduces obesity, brain lipotoxicity and oxidative stress in high fat diet fed rats. Obes Res Clin Pract 12, Suppl. 2, 115-126.

14. Day CP (2006) From fat to inflammation. Gastroenterology 130, 207-210.
15. Wang X, Li Y, Hou C, et al. (2015) Physiological and molecular changes in large yellow croaker (Pseudosciaena crocea R.) with high-fat diet-induced fatty liver disease. Aquac Res 46, 272-282.

16. Jin M, Lu Y, Yuan Y, et al. (2017) Regulation of growth, antioxidant capacity, fatty acid profiles, hematological characteristics and expression of lipid related genes by different dietary $n-3$ highly unsaturated fatty acids in juvenile black seabream (Acanthopagrus schlegelii). Aquaculture 471, 55-65.

17. Jin M, Monroig Ó, Lu Y, et al. (2017) Dietary DHA/EPA ratio affected tissue fatty acid profiles, antioxidant capacity, hematological characteristics and expression of lipid-related genes but not growth in juvenile black seabream (Acanthopagrus scblegelii). PLOS ONE 12, e0176216.

18. Jin M, Yuan Y, Lu Y, et al. (2017) Regulation of growth, tissue fatty acid composition, biochemical parameters and lipid related genes expression by different dietary lipid sources in juvenile black seabream, Acanthopagrus scblegelii. Aquaculture 479, 25-37.

19. Yan J, Liao K, Wang T, et al. (2015) Dietary lipid levels influence lipid deposition in the liver of large yellow croaker (Larimichthys crocea) by regulating lipoprotein receptors, fatty acid uptake and triacylglycerol synthesis and catabolism at the transcriptional level. PLOS ONE 10, e0129937.

20. Schindler M, Pendzialek M, Grybel KJ, et al. (2017) Adiponectin stimulates lipid metabolism via AMPK in rabbit blastocysts. Hum Reprod 32, 1382-1392.

21. Blusztajn JK (1998) Choline, a vital amine science. Science 281, 794-795.

22. National Research Council (2011) Nutrient Requirements of Fish and Shrimp. Washington, DC: National Academies Press.

23. Li J, Zhang D, Xu W, et al. (2014) Effects of dietary choline supplementation on growth performance and hepatic lipid transport in blunt snout bream (Megalobrama amblycephala) fed high-fat diets. Aquaculture 434, 340-347.

24. Li JY, Li XF, Xu WN, et al. (2016) Effects of dietary choline supplementation on growth performance, lipid deposition and intestinal enzyme activities of blunt snout bream Megalobrama amblycephal fed high-lipid diet. Aquac Nutr 22, 181-190.

25. Luo Z, Wei CC, Ye HM, et al. (2016) Effect of dietary choline levels on growth performance, lipid deposition and metabolism in juvenile yellow catfish Pelteobagrus fulvidraco. Comp Biochem Physiol B Biochem Mol Biol 202, 1-7.

26. Qin DG, Dong XH, Tan BP, et al. (2017) Effects of dietary choline on growth performance, lipid deposition and hepatic lipid transport of grouper (Epinephelus coioides). Aquac Nutr 23, 453-459.

27. Koca SS, Bahcecioglu IH, Poyrazoglu OK, et al. (2008) The treatment with antibody of TNF- $\alpha$ reduces the inflammation, necrosis and fibrosis in the non-alcoholic steatohepatitis induced by methionine- and choline-deficient diet. Inflammation 31, 91-98.

28. Wu P, Jiang WD, Jiang J, et al. (2016) Dietary choline deficiency and excess induced intestinal inflammation and alteration of intestinal tight junction protein transcription potentially by modulating NF-кB, STAT and p38 MAPK signaling molecules in juvenile Jian carp. Fish Shellfish Immunol 58, 462-473.

29. Zhao HF, Jiang WD, Liu Y, et al. (2016) Dietary choline regulates antibacterial activity, inflammatory response and barrier function in the gills of grass carp (Ctenopharyngodon idella). Fish Shellfish Immunol 52, 139-150.

30. Lee EY, Park HH, Kim YT, et al. (2001). Cloning and sequence analysis of the interleukin-8 gene from flounder (Paralichthys olivaceous). Gene 274, 237-243.

31. Wei H, Yin L, Feng S, et al. (2015) Dual-parallel inhibition of IL-10 and TGF- $\beta 1$ controls LPS-induced inflammatory response via $\mathrm{NF}-\kappa \mathrm{B}$ signaling in grass carp monocytes/macrophages. Fish Shellfish Immunol 44, 445-452.

32. Wu XT, Yang Z, Ansari AR, et al. (2018) Visfatin regulates the production of lipopolysaccharide-induced inflammatory cytokines through p38 signaling in murine macrophages. Microb Pathogenesis $117,55-59$. 
33. Wyns H, Plessers E, De Backer P, et al. (2015) In vivo porcine lipopolysaccharide inflammation models to study immunomodulation of drugs. Vet Immunol Immunopathol 166, 58-69.

34. Plessers E, Wyns H, Watteyn A, et al. (2015) Characterization of an intravenous lipopolysaccharide inflammation model in calves with respect to the acute-phase response. Vet Immunol Immunopathol 163, 46-56.

35. Pamukcu B, Lip GYH \& Shantsila E (2011) The nuclear factor- $\kappa B$ pathway in atherosclerosis: a potential therapeutic target for atherothrombotic vascular disease. Thromb Res 128, 117-123.

36. Öberg F, Haseeb A, Ahnfelt M, et al. (2009) Herbal melanin activates TLR4/NF- $\mathrm{KB}$ signaling pathway. Phytomedicine 16, 477-484.

37. AOAC (2006) Official Methods of Analysis, 18th ed. Arlington, VA: Association of Official Analytical Chemists.

38. Jiao B, Huang X, Chan CB, et al. (2006) The co-existence of two growth hormone receptors in teleost fish and their differential signal transduction, tissue distribution and hormonal regulation of expression in seabream. J Mol Endocrinol 36, 23-40.

39. Xue L, Yang Q, Xue L, et al. (2008) Molecular characterization of myostatin in black seabream, Acanthopagrus schlegelii. DNA Seq 19, 217-223.

40. Jothikumar N, Cromeans TL, Robertson BH, et al. (2006) A broadly reactive one-step real-time RT-PCR assay for rapid and sensitive detection of hepatitis E virus. J Virol Methods 131, 65-71.

41. Livak KJ \& Schmittgen TD (2001) Analysis of relative gene expression data using real-time quantitative PCR and the 2 method. Methods 25, 402-408.

42. Jiang J, Yin L, Li JY, et al. (2017) Glutamate attenuates lipopolysaccharide-induced oxidative damage and mRNA expression changes of tight junction and defensin proteins, inflammatory and apoptosis response signaling molecules in the intestine of fish. Fish Shellfish Immunol 70, 473-484.

43. Kumar R \& Joy KP (2019) Stress hormones modulate lipopolysaccharide stimulation of head kidney interleukin-6 production in the catfish Heteropneustes fossilis: in vivo and in vitro studies. Gen Comp Endocrinol 279, 109-113.

44. Halver JE (2002) The vitamins. In Fish Nutrition, 3rd ed., pp. 61-140 [JE Halver and RW Hardy, editors]. San Diego, CA: Academic Press.

45. Mai K, Xiao L, Ai Q, et al. (2009) Dietary choline requirement for juvenile cobia, Racbycentron canadum. Aquaculture 289, 124-128.

46. Jiang GZ, Wang M, Liu WB, et al. (2013) Dietary choline requirement for juvenile blunt snout bream, Megalobrama amblycephala. Aquac Nutr 19, 499-505.

47. Wu P, Feng L, Kuang SY, et al. (2011) Effect of dietary choline on growth, intestinal enzyme activities and relative expressions of target of rapamycin and eIF4E-binding protein 2 gene in muscle, hepatopancreas and intestine of juvenile Jian carp (Cyprinus carpio var. Jian). Aquaculture 317, 107-116.

48. Yamamoto Y (1981) Determination of toxicity by biochemical method. In Fishes as Laboratory, chapter 4, pp. 568-574 [N Egami, editor]. Tokyo: Soft Science.

49. Cheng D \& Kong H (2011) The effect of Lycium barbarum polysaccharide on alcohol-induced oxidative stress in rats. Molecules 16, 2542-2550.

50. Takeuchi-Yorimoto A, Noto T, Yamada A, et al. (2013) Persistent fibrosis in the liver of choline-deficient and iron-supplemented L-amino acid-defined diet-induced non-alcoholic steatohepatitis rat due to continuing oxidative stress after choline supplementation. Toxicol Appl Pharmacol 268, 264-277.

51. Zhou F, Shao J, Xu R, et al. (2010) Quantitative L-lysine requirement of juvenile black seabream (Sparus macrocephalus). Aquac Nutr 16, 194-204.
52. Zhou Q, Jin M, Elmada ZC, et al. (2015) Growth, immune response and resistance to Aeromonas bydropbila of juvenile yellow catfish, Pelteobagrus fulvidraco, fed diets with different arginine levels. Aquaculture 437, 84-91.

53. Chen H, Zhang L, Li X, et al. (2013) Adiponectin activates the AMPK signaling pathway to regulate lipid metabolism in bovine hepatocytes. I Steroid Biochem 138, 445-454.

54. Su CC, Chang CS, Chou CH, et al. (2015) L-Carnitine ameliorates dyslipidemic and hepatic disorders induced by a high-fat diet via regulating lipid metabolism, self-antioxidant capacity, and inflammatory response. J Funct Foods 15, 497-508.

55. Wang T, Yang B, Ji R, et al. (2017) Omega-3 polyunsaturated fatty acids alleviate hepatic steatosis-induced inflammation through Sirt1-mediated nuclear translocation of NF- $\mathrm{BB}$ p65 subunit in hepatocytes of large yellow croaker (Larimichthys crocea). Fish Shellfish Immunol 71, 76-82.

56. Aoyama T, Peters JM, Iritani N, et al. (1998) Altered constitutive expression of fatty acid-metabolizing enzymes in mice lacking the peroxisome proliferator-activated receptor $\alpha$ (PPAR $\alpha)$. J Biol Chem 273, 5678-5684.

57. Kerner J \& Hoppel C (2000) Fatty acid import into mitochondria. Biochim Biophys Acta 1486, 1-17.

58. Yang JH (2010) Perfluorooctanoic acid induces peroxisomal fatty acid oxidation and cytokine expression in the liver of male Japanese medaka (Oryzias latipes). Chemosphere 81, 548-552.

59. Ma J, Shao Q, Xu Z, et al. (2013) Effect of dietary $n-3$ highly unsaturated fatty acids on growth, body composition and fatty acid profiles of juvenile black seabream, Acanthopagrus scblegelii (Bleeker). J World Aquac Soc 44, 311-325.

60. Cowey CB \& Walton MJ (1989) Intermediary metabolism. Fish Nutr 2, 259-329.

61. Minghetti M, Leaver MJ \& Tocher DR (2011) Transcriptional control mechanisms of genes of lipid and fatty acid metabolism in the Atlantic salmon (Salmo salar L.) established cell line, SHK-1. Biocbim Biophys Acta 1811, 194-202.

62. Takai T, Saito Y, Yamamoto K, et al. (1988) Developmental changes of the content of acetyl-CoA carboxylase mRNA in chicken liver. Arch Biochem Biophys 266, 313-318.

63. Wakil SJ (1961) Mechanism of fatty acid synthesis. J Lipid Res 2, $1-24$.

64. Qian Y, Li XF, Zhang DD, et al. (2015) Effects of dietary pantothenic acid on growth, intestinal function, anti-oxidative status and fatty acids synthesis of juvenile blunt snout bream Megalobrama amblycephala. PLOS ONE 10, e0119518.

65. Barbuio R, Milanski M, Bertolo MB, et al. (2007) Infliximab reverses steatosis and improves insulin signal transduction in liver of rats feed a high fat diet. J Endocrinol 194, 539-550.

66. Chou MC, Chang R, Hung YH, et al. (2013) Antrodia camphorata ameliorates high-fat-diet induced hepatic steatosis via improving lipid metabolism and antioxidative status. J Funct Foods 5, 1317-1325.

67. Varga T, Czimmerer Z \& Nagy L (2011) PPARs are a unique set of fatty acid regulated transcription factors controlling both lipid metabolism and inflammation. Biocbim Biophys Acta 1812, 1007-1022.

68. Dong YW, Jiang WD, Liu Y, et al. (2017) Threonine deficiency decreased intestinal immunity and aggravated inflammation associated with $\mathrm{NF}-\mathrm{\kappa B}$ and target of rapamycin signaling pathways in juvenile grass carp (Ctenopharyngodon idella) after infection with Aeromonas bydrophila. Br J Nutr 118, 92-108.

69. Zhang A, Chen D, Wei H, et al. (2012) Functional characterization of TNF- $\alpha$ in grass carp head kidney leukocytes: induction and involvement in the regulation of NF- $\mathrm{KB}$ signaling. Fish Shellfish Immunol 33, 1123-1132. 